\title{
Embodiment as Embodiment of
}

\author{
Paul Bowman \\ Cardiff University
}

\begin{abstract}
This chapter presents embodiment as a uniquely challenging problem for certain traditions and approaches to scholarship, particularly those that are implicitly or explicitly organised by the aim of establishing meanings. Such an orientation is exemplified by semiotics, of course, but the chapter argues that even approaches designed to critique semiotics and other forms of 'logocentrism' (or, approaches that focus on words and meanings) ultimately struggle in the face of dealing with aspects of embodiment. Even Derridean deconstruction - which was developed as a strident critique of logocentrism - struggles to move beyond the focus on words and meanings. So, the question becomes one of whether scholars interested in embodiment should reject or move beyond these kinds of approaches. Drawing on a loosely autobiographical narrative that touches on aspects both of the author's academic training and his investment on martial arts and other physical cultural practices, this chapter argues that it is not simply possible to 'reject' or 'move beyond' the logocentrism of traditional 'search for meaning' orientations. It argues that even though this may seem relatively passé, 'embodiment' is still very productively conceived of as 'embodiment of' - i.e., as the embodiment of something else; specifically, as the performative and interpretive elaboration of something other that is received, perceived, felt, constructed, believed, assumed or otherwise lived as being either an aim, ideal, desire, objective, fantasy, or as a norm, or indeed as the warding off of something undesired or feared. The chapter poses questions of how to 'capture', 'convey' or 'communicate' embodiment in words, and interrogates the necessity of the current hegemony of the written word in academia. But it seeks to avoid any kind of evangelism about new approaches or understandings of embodiment, and twists at the end to propose that even certain forms of what we perhaps too quickly regard as 'enlightening' or 'emancipating' practices and techniques of embodiment might be regarded as traps, or indeed prisons.
\end{abstract}

\section{Keywords}

Embodiment, knowledge, martial arts, poststructuralism, deconstruction, logocentrism 


\section{Preface: Trigger warning: Autobiography Alert}

Please beware: in what follows, I am at times going to be quite shamelessly autobiographical. But this is not merely self-indulgent. Rather, it is because I think that personal anecdotes can offer an economical way of getting a lot of concerns on the table quickly, by conveying the ways that some key problematics around 'embodiment' have arisen in relation to my research and thinking, and the ways they have both vexed and stimulated me. ${ }^{1}$ But not just me as some kind of unique, isolated individual; rather me as an academic who has searched for theoretical and/or practical academic ways out of many of the problems. So, my hope is that when you read about 'me' here, you will think less about me and much more about 'we'. Either way, please have patience with the autobiographical elements of what follows. They are doing some heavy lifting. Here goes.

\section{Introduction: A Brief History of No Body}

I have always loved martial arts and I have always loved writing. I loved martial arts films as a child. As a teen I tried to learn how to do the flashy moves that I saw on screen. At the same time, I found writing essays for school to be one of the easiest things I'd ever been asked to do. Hence in the school system I became what was called 'good at English'. In fact, although I far preferred other subjects (economics, geography, art), it transpired that, with no effort at all, for some reason, I started to come top in English. In due course, without really knowing anything at all about it, I was given the chance to go to university. Following a path of least resistance, I pragmatically elected to take a subject I was 'good at' and found easy, simply because I was good at it and found it easy (and because it had the added attraction of minimal contact hours and maximal assessment by essay). So I studied English. The irony was that I came from a barely literate working class family in which no one had ever passed a written exam and I myself did not particularly like reading. Writing, yes. Reading, less. Either way, I was regarded as a kind of freak of nature by my father and brothers, because I could and would read and write, I was left handed, and I spent most of my time doing things that they did not do and did not understand or regard as 'proper activity', as they did not visibly involve making, fixing, altering, tinkering, moving and visibly doing. ${ }^{2}$

At university I genuinely loved literary theory from the moment I met it (formalism first, then structuralism, poststructuralism and - my favourite at the time - semiotics) 
but I was increasingly bored by literature. After my degree, a friend told me about a subject called cultural studies. I looked into it. I did an MA, using erstwhile 'literary' theory (now redubbed 'cultural' theory) to look at more interesting things than literature - such as martial arts films, music videos, the rise of body consciousness in men via bodybuilding, and the political possibilities of stand up comedy. I was invited back to do a PhD. What did I want it to be on? Something about 'theory' had hooked me. I chose to interrogate the political theory of Ernesto Laclau and Chantal Mouffe (primarily Laclau and Mouffe 1985). There was no 'body' there. Just words, institutions, mechanisms, political processes, hegemonies, relations of articulation, power/knowledge, semiotics, interpellations ${ }^{3}$ conflicts of interpretation, and so on.

Throughout my PhD studies and in the years immediately thereafter, I kept writing about problems in political and cultural theory using poststructuralist approaches (see Paul Bowman 2007). But all the while what I wanted, more and more, was to write about a completely different thing - martial arts, in terms of what we are here calling embodiment. However, the problem was that I was immersed in the world of problematics and approaches and paradigms that were primarily kitted out to deal with very different things - principally, the philosophical critique of logocentrism and what Derrida called the 'metaphysics of presence', conceived or as key parts of the wider ethico-political deconstruction of essentialisms of all kinds.

\section{Being Haunted by the Body}

It is probably worth remembering that Jacques Derrida (the so-called 'father' of deconstruction) was always widely denounced and defamed by opponents as someone who did not believe in and who tried to deny the existence of reality, or the reality of existence (for discussion see Derrida and Weber 1995). I mention this unfair critique here not because it is correct but because there is something close enough to a spectral or chimerical grain of truth in it to illustrate the predicament I was in. For, if deconstruction does not simply deal with 'things' - 'real things', like, say, our bodies - then surely trying to use Derrida to think about embodiment is a bit like trying to use a chocolate teapot to make tea. Nonetheless, when I did eventually, tentatively, (re)turn to trying to write about embodiment, I did so via the only means I knew: Derridean deconstruction, poststructuralist discourse theory, and Barthesian textual analysis (Paul Bowman 2008, 2010).

This may sound a bit like trying to dig your way out of a hole, or like Slavoj Žižek's 
joke about searching for a lost key under the light of a streetlamp rather than in the surrounding darkness where you actually lost it, because you can't see anything over there in the dark. But you start from where you are, you think with the tools and in the terms you have learned to think with, and you write the way you know. I was going to say 'you write about what you know about', but I don't think that's entirely correct: I think I am more inclined to write about what I wonder about. So my first attempt to deal with the impact and importance of martial arts on the lives and minds and bodies of people (like me) took the form of using the approaches of Derrida, Laclau and Stuart Hall to account for the emergence and to assess the significance of the 'kung fu craze' of the 1970s. My very first attempt was a conference paper called 'Enter the Derridean' which reflected on the impact and enduring significance and effects of Bruce Lee films on people's imaginations and activities and lives and loves.

At the same time, however, it was important to me not to consign 'Bruce Lee' and 'martial arts' to the status of being treated as mere examples, to be (ab)used only in order to unproblematically 'prove' a certain theory - in this case, the theory of 'discourse' as developed by the likes of Ernesto Laclau and Stuart Hall, following on from Michel Foucault (mixed with a lot of Antonio Gramsci). So, as the title of my first paper on this ('Enter the Derridean') hopefully suggested, the work was also attempting to assess the emergence not only of what might be too easily dismissed or categorized as the kung fu 'craze' - or some kind of 'subculture' - but rather the emergence of the 'discursive formation' of cultural studies, cultural theory, and deconstruction themselves. After all, all of these things took off during the same kind of period, yet we tend not to regard academic movements as being crazes or subcultures, do we? We tend rather to connect them to wider issues and problematics and to dignify them with labels like 'intellectual developments'. Reciprocally, I wanted to accord the same dignity to figures like Bruce Lee and developments like the uptake of 'Asian martial arts' in Western popular culture. These were not mere crazes. Nor should they be categorized as 'subcultures'. Such designations keep the scholarly gaze that creates them safely free from the same kind of scrutiny that it applies to everything else.

Papers like that (which was eventually worked up and worked into the first chapters of my book Theorizing Bruce Lee (2010)) were my first baby-steps into working towards matters of embodiment. So I suppose you could say I followed an eccentric route into such waters. (Or maybe I wasn't even in the waters yet, but still stuck on 
the rocks, looking around me for a viable sandy route down to the water.) For, overwhelmingly, my approach was textual (principally organised by looking at films, books and magazines); it was self-consciously part of a tradition (cultural studies) that had a strong commitment to redeeming so-called 'popular culture' from the stigma of being branded trivial and inconsequential; it was informed and organised by paradigms that focused on macro-political discourses; and (while Barthes' approaches extended to audiovisual culture, Derridean deconstruction and much poststructuralism was principally a critique of 'logocentrism') my approach, despite my best intentions, was arguably very much focused on words and pictures.

\section{In The Beginning Was The Word - and Pictures}

Of course, things are not so simple. In the history of the notion of 'discourse', the work of Michel Foucault looms large. And there are two obvious sides to Foucault: first, his studies of the effects of arguments, ideas, texts, legislations and institutional operations on (second) the human subject, in mind, body, flesh, blood, muscles, skills and disciplines. So there are clearly at least two directions that a Foucaultinspired or informed 'discourse approach' could go. One is macro-historical and/or institutional. The other is focused on minds and bodies and persons and people. All of my prior training (indeed, all of my disciplining) had been in the world of the first orientation. So, when I tried to turn to the question of things like non-logocentric knowledge and embodiment, my efforts essentially took the form of conceiving of embodiment as embodied discourse. That is, I understood embodiment as always and necessarily involving discursive factors and forces (words and pictures). These forces found their actualization in and as aspects of embodiment via what may be called 'performative elaborations' or 'performative interpretations'. (I take these terms more from Jacques Derrida (Derrida 1994) than Judith Butler (Butler 1990).) Accordingly, embodiment in my thinking was always likely to be associated with wordy or audiovisual discursive injunctions, imperatives, ideals, and so on.

So, my approach could be accused of believing that 'in the beginning was the word'. And pictures. But pictures translated into words. And actions. It is definitely the case that I have always read many 'words and pictures' as being - or becoming injunctions (or Foucauldian discursive statements), such as: 'aspire to be like this', or 'desire this'. Doubtless this orientation is a residue of the influence that Barthes' arguments in Mythologies (Barthes 1957) had on my thinking. Indeed, I still regard almost any deliberately selected and crafted audiovisual textual images of people, 
places and things, to be injunctions: aspire to this, desire this, be like this, or their obverses - avoid this, reject this, be disgusted by this, and so on.

This is hardly a radical position to take. Many others go much further. In a different context, and in a slightly different direction, Andrew Barry goes significantly further than this, for instance. In Political Machines, he notes that even the 'factual' world the world of 'facts' - is constructed and works in terms of injunctions. Neither 'data' nor 'information' are ever neutral. As he puts it: the existence of data about, say, smoking and mortality, or diet and diabetes, and so on, implies a subject who 'needs' that 'information' and who should respond to its implications and act accordingly because of it - give up smoking, lose weight, etc. (Barry 2001). This is relevant to embodiment because it would mean that any subsequent actions undertaken in light of the 'facts' or 'information', leading to body modification or enskillment (running skill, say, or the production of a 'yoga body' (Singleton 2010)) would amount to the embodiment or performative interpretation or articulation of a certain kind of discursive injunction.

In my approach to bodies, embodied knowledge and bodily practices (specifically, martial arts), I have tended to prioritise cases of the 'translation' of visual material (say, moving or static pictures of someone like Bruce Lee) into being a kind of injunction ('Be like this! Desire this!') or indeed a Foucauldian 'statement' (Foucault 1970), and from here, on into the transformation of lived practices - and hence the transformation of bodies, bodily skills, lifestyle norms, values and sensibilities, and so on (Paul Bowman 2010, [b] 2013). But the key point has always been that in the case of moving or static pictures of Bruce Lee, such 'messages' were not solely translated into words. Rather, in the case of words and pictures about martial arts, such cultural 'messages' were and are often translated by people into physical practices - the taking up of new activities or living life according to new values and different orientations. The 'creation myth' image here is one of children and teens seeing a martial arts movie for the first time and leaving the cinema making Bruce Lee catcalls and trying to do flying kicks (the exemplary work on this creation scenario is Brown 1997). Over the coming days and weeks and months, how many of such erstwhile spectators went on to seek out a martial arts class? The evidence (or at least the accepted narrative) says many. This means that embodiment is also often supplemented by media spectacles - or, in other words, mediatized (Paul Bowman 2017). 
In turning to the impact of martial arts films on people and on popular culture, I was trying to step away from the world of institutionally and macro-politically focused poststructuralism and to start thinking and researching the ways that cinematic images have functioned effectively in and as fantasy identifications and other forms of psychic/psychological processes to inspire and induce certain embodied practices. My first focus was Bruce Lee and I was interested in martial arts practices, specifically. Of course, this means that I was still entirely subjected to thinking of 'culture' and 'subjectivity' (embodied or otherwise) in the terms of poststructuralist semiotics, in which everything becomes signifiers sending messages and pointing to other signifiers, and so on (see Silverman 1983). Consequently, I don't really think that any of this work actually or simply got to the matter of 'embodiment'. It focused on the nexus of media representation, identification and fantasy, conceived as a kind of motor that inspires and/or sustains physical practice.

Phrased like this it all sounds very technical and grand. Yet maybe we don't even need the trappings and baggage of the language of psychoanalytical cultural theory to describe it. Maybe we could just as easily talk about people's beliefs or hopes or ambitions being the things that generate and sustain their practices. If we think of the common case of running, for example: people can (and do) talk a lot about why they run (for health, to lose weight, to raise money for charity, for a sense of wellbeing, or because they are 'addicted', and so on). But none of these words give us any insight into any matters of embodied running, from anything about the experience to any other kind of (non-wordy) insight. Rather, such conversations about running are often chiefly about reasons for running or problems and achievements in terms of measuring the activity. When we try to probe the experience of running itself, our words often come up short. There seems to be a dearth of terminology, of vocabulary, of concepts. There are shared 'technical' phrases, and shared descriptions: we can speak of muscle cramps, how we might feel like we can't get enough air into our lungs, how we hit the wall, and so on. But other than this, the experience of running in the discourse of runners often seems to find its way out into speech and language as nothing other than euphemisms and value judgments about something that cannot otherwise be expressed. The experience of a run was great or terrible or hard or easy or exhilarating or harrowing, and so on. But what was the 'that' that we are saying was good or bad or hard or easy or fun or challenging?

\section{How To Do Things With Guts}


Before we rush headlong into saying that we are now in the realms of phenomenology, we should note that what we are facing here is a general problem of signification. To translate something from an individual experience into words and meanings always requires a move away from the perceived essence or heart of the matter, via a necessary (invented, poetic) connection with another coordinate. An experience is like one thing, and not like another thing; it can only ever be evoked through comparison, analogy, metaphor, contrast, and so on. Admittedly, the communication of a non-linguistic event, phenomenon or experience, is a particularly knotty kind of semiotic problem, but it is a semiotic problem nonetheless. Like everything, attempting to signify 'that thing' will always involve composition, construction, and a perhaps ultimately impossible or forever unsatisfying effort of translation.

All of this has been reflected upon since at least the time of Charles Sanders Peirce. People have found fascinating ways out of this abyss, or ways to bridge it, or bypass it. But I have always insisted on remaining frustrated by any apparent solution or attempt to dissolve this problematic. I have always felt the need to hold onto the tensions, gaps, disjunctions, aporias, absences and irrelations between experiences and words. This is because trying to keep ahold of this tension imposes a gnawing, generative problematic. Loïc Wacquant expressed it well, I think, when he wrote, on the subject of learning boxing:

How to go from the guts to the intellect, from the comprehension of the flesh to the knowledge of the text? Here is a real problem of concrete epistemology about which we have not sufficiently reflected, and which for a long time seemed to me irresolvable. To restitute the carnal dimension of ordinary existence and the bodily anchoring of the practical knowledge constitutive of pugilism - but also of every practice, even the least 'bodily' in appearance - requires indeed a complete overhaul of our way of writing social science. (Loïc Wacquant 2009: 122)

This passage has long stood out for me as a near perfect statement of a problem that animated - or rather agitated, aggravated, frustrated, sometimes paralyzed - me for quite a while. I still don't feel like I have actually resolved it.

Wacquant himself says his attempt to solve the problem took the form of adopting a strategy of mixing different styles of writing, different modes of address: sometimes 
literary/descriptive, sometimes confessional, emotional, ethnographic, sometimes analytical, and so on. The purpose of using different modes of address and manners and conventions of writing when talking about his experiences of learning boxing (Löic Wacquant 2004) was his attempt to find a way to capture and convey as much about 'the comprehension of the flesh' as possible in the medium of words. Different modes and conventions of address could be said to capture and convey different dimensions, so Wacquant's 'solution' is one of mixed modes and multiple voices. Such an approach both acknowledges and attempts to outflank the kind of abyss that often seems to exist between (the experience of) embodied know-how and the communication of that embodied knowledge in words.

A few things always jump to mind when I think about this. One is the expression 'one showing is worth a thousand tellings'. Another is 'that which cannot be said can be shown'. Another is 'he who knows does not speak, he who speaks does not know'. And still another is from a scene in a David Lodge novel in which someone considering studying psychology at university (because they want to know how people's minds work) is advised by a literary scholar that if they really want to gain an understanding of human psychology they'd be better off studying novels.

These fragments spring to mind here because Wacquant's adoption of different literary modes acknowledges that the attempt to convey embodied knowledge via words will always require different conventions: the academic, philosophical or phenomenological will be helpful, but partial and incomplete; as will 'thick description'; as will poetic, emotive, rhetorical and otherwise literary language. Taken together, perhaps the effect will be more rounded than one style of writing alone, or in isolation. But, still, all will in some sense fail. This is because the act of moving from the guts to the intellect requires a leap, an act of bridging, connecting different worlds, translation, and catachresis. Catachresis refers to 'drawing a face on that which does not have a face', or indeed embodying that which doesn't really have a body (the cliff face, the table leg) (Sacks 1978; Spivak 1990).

Viewed from here, even Wacquant's choice of the word 'guts' can be regarded as hugely metaphorical and poetic. It was doubtless chosen precisely because of its complex historical and cultural overdetermination: its residual, resounding emotive, evocative force. For, the word 'guts' has a range of mythological associations, all of which suit Wacquant's purposes. These associations range from conjuring up senses of 'the body' to 'bravery' via 'the abattoir' and even 'peasant food' or 'working 
class fare from days of yore', and so on. So, it sounds gritty and earthy and manly and basic and essential and real. Yet, the embodied knowledge of pugilism both is and is not a knowledge of, from, or centred on or in 'the guts'. Guts are involved, but that still doesn't actually capture what we are trying to convey here, or what 'guts' evokes (catachrestically, rather than metonymically or synecdochically).

For, what is Wacquant trying to convey with the word guts? I think he is talking about a specific kind of enskillment and that general kind of enculturation that he refers to via Bourdieu's theorisation of 'habitus' (Bourdieu 1979; Loïc Wacquant 2013). Of course, probably more literally important than 'how to go from the guts to the intellect' would be 'how to go from things such as balance, proprioception and timing skills to the intellect'. ${ }^{4}$ But none of these terms sound quite as good as 'guts' as a contrast to 'intellect'.

Rather than doing something like calling Wacquant a sophist or dualist or anything like that, it seems more reasonable to acknowledge the inevitability of imprecision, evocation and contrast; and to know that to go down the line of trying to escape poetic language by trying be literal or specific, we would quickly become ensnared in the paradox of blason poetry. As a lover's hymn for the woman he desires, the blason attempts to itemise and wax lyrical about each and every part of a desired lady's beautiful body - to try to isolate and comment on precisely why and how it is so beautiful and attractive. The problem is that in attempting to do so, the overall image that is created becomes heterogeneous, improbable, often ugly, always literally preposterous, and just generally ridiculous. In blason poetry, women come to be made up of the cobbling together of things like flowers, apples, milk, silk, oceans, precious stones, music, landscapes, stars, planets, feathers, and so on - or indeed 'sugar and spice and all things nice'.

Nonetheless, just because something requires a work of translation in order to be expressed or communicated, this should not deter us from trying. Derridean deconstruction essentially held that a true, complete or adequate translation was ultimately impossible. But this never stopped dyed in the wool Derridean deconstructionists from translating the texts of Derridean deconstruction into language after language. Similarly, embodied knowledge need not be regarded as something ineffable, inexpressible or mystical, as if it were the Tao of Taoism or indeed the divine in any kind of negative theology. 
So, despite its problems, Wacquant's statement of the problem stands, as a challenge. His proposed solution of mixed modes and manners of expression even seems reasonably acceptable. But it we accept it, our questions should henceforth become something like: what concepts, metaphors, images, vocabularies and genres and conventions of writing are best able to convey embodied knowledge, skill, technique, experience?

This is one viable and valuable line of exploration. But before rushing into it, maybe there is further cause for hesitation. For, in posing things in this way, maybe we are still being unnecessarily blinkered. Maybe we are not seeing the bigger picture - or once again perhaps we are insisting on looking for our lost keys under a streetlight rather than in the surrounding darkness where we actually lost them - or trying to dig our way out of a hole. For, if we were to take a slightly broader view, perhaps the real question should be: is the written word actually capable of communicating any of this? Or (more modestly put), might other, newer media be any better?

\section{Simulacra and Stimulation}

The recently established Journal of Embodied Research gives resounding and unequivocal answers to these questions: no, the written word can't, or isn't simply the best, or should now be regarded as inadequate and inferior, when assessed in relation to the potentials or propensities of new audiovisual media technologies. The latter far outpace and utterly reconfigure the possibilities for capturing, conveying, communicating and developing knowledge and discourse about embodiment. Ben Spatz theorised this in his important book What A Body Can Do (Spatz 2015). It was principally he who went on to establish the agenda of the Journal of Embodied Research in light of his earlier work.

As someone who remembers Jean Baudrillard's arguments about the supposed loss of the real, in and because of the audiovisual image, I delight in the inversion and displacement of the gauntlet thrown down in the editorial manifesto of the Journal of Embodied Research. For its argument seems to be precisely the opposite of the Baudrillardian hypothesis of the loss of the real. Rather, proposes the journal, it is actually going to be by exploring and developing the capacities and propensities of audiovisual media that academics and other researchers will be able to establish a kind of 'royal road' to the body, in terms of audiovisual studies of embodiment, skill, practice, experience, and the establishment of embodied knowledge. 


\section{The Body of Knowledge}

Unfortunately, to argue that new media technologies trump the written word when it comes to establishing, documenting and discoursing academically on embodied knowledge (thanks to the creative and innovative audiovisual texts that they can allow us to construct), we run into a whole new problem. This is the problem of the legitimation of different kinds of texts, such as audiovisual media texts, in the face of the ongoing absolute hegemony of the written word, as representing the pinnacle and yardstick of academic propriety within academia.

That is to say, despite innovations here and there, academia (like other institutions) continues to produce principally written documents. So, innovations like the Journal of Embodied Research are posing a direct challenge to this hegemony, not by rejecting writing, but by attempting to massively expand the range of possibilities for new kinds of academic writing - including inscription, analysis and discourse, not just 'documenting'. (For a compelling discussion of this, I encourage readers to read the final chapter of Spatz's What A Body Can Do (2015).)

To restate all of this via a deliberately naïve rhetorical question: if we want to translate from embodied experience and into some other mode, manner or medium, why do we continue to single out and prioritize writing? We live in an audiovisual age, one that has been called 'post-literate', as it is characterised by the waning of older kinds of literacy, and the emergence of newer kinds of literacy (Chow 2012; Paul Bowman 2013a). Indeed, even the word 'literacy' reveals the residual hegemony of the written word. Yet book reading is increasingly being supplanted by different kinds of interaction with different kinds of audiovisual text or platform, many of which can hardly be called 'reading' anymore, even if we still treat them as if they are. Yet, the era has past in which the dominance or hegemony of the written word was unquestionable and necessary, in which knowledge and skills centring on written cultural forms such as the novel or poetry equalled both the yardstick and the pinnacle of necessary learning.

Like the once-presumed imperative educational value of teaching children to be able to locate countries and cities on a map of the world, certain forms of 'cultural literacy' wither and die. ${ }^{5}$ Educational imperatives and values always in some sense reflect the concerns, orientations, technologies and values of their times and places (Young 
1992). Despite Prime Minister Margaret Thatcher's attack on the arts and humanities, I grew up believing in the almost unquestionable and surely timeless value of 'English literature'. It always felt like there might be 'something about class' involved in learning to love it (Bourdieu 1984), but it was only much later that I learned of the Eurocentric colonial-management basis of subject's origins and development (Anderson 1991).

Of course, we are definitely now not simply or directly talking about embodiment here. We are now talking about the ways that attempts to advance the study of 'it' (singular or plural, noun or verb) reciprocally challenge established conventions that ostensibly have nothing to do with bodies, the body, or embodiment. But my sense is that this will (maybe even should) always be the case. The body isn't simply one thing. We so easily say 'the body' - but there is not just one body. And there are not just lots of different ethnic and gendered and sexualised and classed and interpellated and self-identified bodies either. So 'politically correct' pluralisation doesn't get to the heart of the problem - because nor is there simply one body for one person. All of this and more is why the the word embodiment, for me at least, will continue to imply at least a sense of referring to 'the embodiment of something else'. As mentioned earlier, maybe the fact that I think and see it in this way is a symptom of the eternally returning force of my schooling in poststructuralism and deconstruction. Nonetheless, I also think that much scholarship on the body, on bodily learning, embodied skill, and so on - at least in and around the area of martial arts that I most frequently read - supports my sense of this inevitability. In fact, if embodiment doesn't mean 'embodiment of', then I struggle to see what it means.

In a way, this is fine. I am unlikely ever to renounce my 'secondary habitus', which took the form of my schooling or (antidisciplinary) disciplining in all things poststructuralist. So I am quite content to discover that when reading studies that are ostensibly about embodiment I actually find that I am reading just another book or article about nationalist projects, institutional strictures, pedagogical relations, ritualistic fetishizations of orientalist fantasies, and so on. I'm happy because often this is great scholarship, and it feels really stimulating and important.

But, thinking about it now, one thing that strikes me is that as I become more and more immersed in reading and researching 'the body' in different ways, the force of the problematics that first captivated me have lost some of the once powerful hold they had on my imagination. For instance, I can remember the extent to which I used 
to wonder and worry and fret and work away with the 'guts to intellect' problematic on my mind, in my mind; but as I have dug down into various schools of scholarship that have engaged with embodiment in various ways, this problematic has lost its prominence, albeit (for me) without ever having been resolved.

Maybe this is what 'becoming disciplined' is like. It is as if, by reading more in ethnography, anthropology, performance, and so on, and becoming more literate, more circumspect, more well informed about the work being done in these fields, the prominence of this once agonising problematic has more and more settled down (rather than having been resolved); as if I have simply and without really realizing it just become used to it, and stopped seeing it, or stopped feeling it. Surely this is what 'discipline' is, or does - it gets you used to, so the thing that once seized hold of your soul is no longer quite so striking, shocking, disruptive, forceful, jolting, deforming, transforming.

Or perhaps it's just that new and equally fascinating problematics have arisen and seized hold of my soul: questions of how embodied practices (such as martial arts kata, forms, patterns or taolu) emerge, stabilize, stay the same over time or mutate, deform, transform, and so on; questions of how bodily skills and types of knowledge are conveyed or communicated from one person to another, how or whether that happens without omission, addition, or transformation; whether certain types of practice are isolatable or abstractable from larger formations, and whether 'elements' or 'components' of supposed entities are 'portable', and if so, whether they stay the same, or what they become. I know there are many in depth studies of the complex stabilizations, transformations and deformations of complex cultural practices (some of my favourites include Wile 1999; Frank 2006; Singleton 2010; Sieler 2015; Judkins and Nielson 2015, but there are many more), but on a smaller more personal level I often find myself consumed with questions about whether you could learn push-hands 'properly' without learning taiji forms and/or qigong standing postures; what the borders and boundaries are between, say, qigong and yogic pranayama breathing; whether the training ethos and values of taiji practice could or should be applied in escrima training, or whether there is an absolute and necessary divide, how and where and why this applies, and so on. These are the kinds of questions that currently consume me.

Yet, as all consuming as such questions sometimes feel, I always seem to want to keep them amateurish. I want to keep them rough and ready. As soon as they are 
too easy to articulate, or as soon as an academic idiom steps up and presents itself as being totally able to handle, conceptualise and communicate the problematic, I tend to feel like they have vanished. To resurrect Paul de Man's phrase, I tend to cleave to the idea that the real should involve at least some 'resistance' to theory (De Man 1986). If there's nothing resistant there, no friction or drag, then it starts to feel like I'm no longer dealing with something real, and maybe just completely immersed in a kind of non-referential theory.

In this and other ways, my amateurish and principally autodidactic (or at least iconoclastic) physical training informs much of my intellectual and academic thinking and writing. More precisely, my worries about my physical training practices inform many of my academic reflections and ruminations. And I do worry deeply and profoundly and at length about my physical training. Questions that keep me awake at night and wake me up in the morning tend to take the form: Can I combine this with that? If I do this do I have to do that? What happens if I add this but omit that? And so on. Yet, despite obsessing over so many questions, I almost never ask an authority figure to tell me the answer. This is less because I fear reprimand from former martial arts teachers for asking heretical questions or abusing tradition with the way I am doing things now, and more because my academic studies have alerted me to the very real likelihood - indeed, inevitability - that even the most 'authentic', 'traditional' and 'masterful' of authentic, traditional masters - on some fundamental level - do not know 'the truth' and are inevitably either making it all up themselves or religiously repeating something that was really basically just made up.

Somebody had to make it up. It had to come from somewhere. And despite what people like to believe, it almost certainly hasn't come from some unbroken millennialong tradition. If it wasn't made up by your teacher, it was almost certainly modified by them (Paul Bowman 2016; P. Bowman 2016). So, where does that leave us? Or rather, where does it take us?

Perhaps if I were entirely content and confident that what I were doing in my physical practices were right or true or correct or best or essential then maybe I would not worry so much about whether, say, a Lacanian language (of symbolic lack and imaginary plenitude, and so on) or a Deleuzean language (of affect and rhizomes and reterritorializations, and so on) were more or less appropriate for capturing or expressing the truth or reality or relevant features of my embodied experiences. But I am not. I do not have complete faith in the truths and axioms and tenets of either 
realm - neither my martial arts practice nor my academic practice.

\section{For better or for worse, in sickness and in health}

I suspect (sometimes I worry) that my irrepressible skepticism might make me a better theorist but a worse martial artist. The promiscuity of my martial arts practice has definitely broadened my perspectives, and enabled me to grasp and to feel confident enough to talk about a wider range of practices. But if I had been more faithful to fewer martial arts, surely I would be a much better practitioner. However, I have never been able to limit myself to one established set of practices, or one paradigm. I do one thing and then I worry that I am not doing another, and inexorably I flip over into practicing that other thing for a period of time, until I worry that I am not doing something else, so I flip across to that; and then I flip back, a bit like the Chinese elements, or rock-paper-scissors, each thing overcoming another and being overcome by another. If I am obsessing about taiji and qigong, all of a sudden I will find myself consumed with worry that I am not engaged in enough hard-core pugilism or grappling and I will flip over to that. Then I will worry about the damage I feel I am doing to myself and flip into more therapeutic practices, like yoga. Then I will worry about strength, and flip into weightlifting. Then I will worry about losing my taiji sensitivities and flip back into that. So, perhaps my embodiments, the things I could be said to embody, seem to involve worries about what I am not doing and constant crises of confidence and faith.

Yet, despite my eternally-returning skepticism and rhythmically predictable crises of faith, this does not mean that I lack faith or that I am somehow emancipated from belief. Rather, I am constantly plagued by doubts and worries. Worries about some vague, unspecified Terrible Thing that might happen if, for instance, I were to stop doing my taiji forms, or to stop doing standing qigong, or the associated stretches that are said to be necessary supplements to the practice of the standing postures. Or worries about what might happen if I were to stop sparring.

These are, of course, my own personal existential matters, that might perhaps only be connected to my own sense of self and my own sense of identity. Certainly, you could psychoanalyse me and easily diagnose me as screwed up in any number of ways. And that would be fine. But, as I said at the beginning, although I am talking about myself here, I believe the implications of what I am discussing extend beyond my own personal idiosyncrasies or neuroses. The connections between physical 
practices, senses of identity, and wider discursive movements and ideological formations are not just related to psychology. They are a large part of anthropological, ethnographic, sociological and cultural studies approaches to embodiment. I mention crises of faith, anxieties, worries about sticking to one course or taking another, taking a bit of one course and combining it with another, and so on, because I think it suggests something important about 'embodiment'.

For instance, I have a weird relationship taiji. I have practiced taiji for nearly two decades, yet I no longer feel like I 'really believe in' taiji as a martial art. I also don't really rate it as a physical exercise or health-giving practice. (I would rate qigong, yoga and weight lifting far higher.) And yet I cannot bring myself to stop practicing taiji. And yet I find myself unable to articulate clearly and directly what my investment in the forms is.

For me, this casts a very real kind of light (or shadow) on Peter Sloterdijk's recent argument that religions are essentially misrecognised or 'misinterpreted anthropotechnic practice systems' (quoted in Spatz 2015: loc 517). For it suggests that taiji has the status of a kind of religion for me. Or, worse, a very particular kind of relationship to religion: the relationship of a non-believer who still goes to church. The automatism of the form seems to have produced a compulsion to repeat. Here we are in the orbit of Althusser, Pascal and Freud, and of the profound effects of institutions and ideologies on pathologies (Althusser and Brewster 1971). The forms are pleasurable, to be sure; they definitely used to mean certain things to me, and I definitely used to believe that they were, if not 'actual' combat, at least about combat. And yet, what are they to me now? They seem to have the status of a kind of 'warding off' of something terrible that might happen were I to stop doing them; a kind of gently pleasurable yet inexorably compelling exorcism ceremony, that I feel drawn to and feel I have to perform. ${ }^{6}$ (This thought about taiji practice as 'warding off' something terrible that might happen if I were to stop doing taiji often intrudes to bother me when I am performing the taiji move called 'ward off'.)

I raise all of this at the end because I think it is important not to be too evangelistic about the possibilities of embracing embodiment, in academic study and in daily life. It is definitely marvellous to be 'in touch' with one's body, to become differently enculturated, enskilled, enabled, even emancipated from many problems that can plague people who are not 'in touch' with their bodies. But, at the same time, we need to realise that our forms of embodiment can also become our bondage. I 
remember reading an article about the effect of nicotine on the body in a "how to give up smoking' article. The author wrote that smokers feel like nicotine gives them something. But what smokers need to realise is that nicotine has actually originally stolen something from them, and they are driven to return to nicotine in order to temporarily remember what it is like to be reunited with the stolen thing. That thing is the feeling of calmness and not-craving-nicotine that non-smokers don't even realise they always and already have, and that smokers miss and attempt to recreate, by smoking another cigarette.

That article certainly helped me to establish a perspective that helped me to give up smoking. And that's definitely good, right? Smoking is definitely bad, right? But what if the nicotine-effect extends to other things? I remember as a teenager and twentysomething feeling compelled to go to the gym to lift weights. I had to. I felt like a bicycle tyre with a slow puncture, and that I would deflate to nothing if I did not keep going and pumping up my muscles. Strength training and bodybuilding was certainly very enabling for me. But it also trapped me. I'm still not sure that I have actually escaped from the clutches of that particular affliction. But the same is also true with taiji, qigong, yoga, sparring. In some respects, they feel like a life sentence. And like the 'lifers' in The Shawshank Redemption, my worry is that I would not (will not) know how to cope, what to do, how to be, without it, or outside of it.

Is that just me? In any case, it's a good thing, right?

\section{References}

Althusser, Louis, and Ben Robert Brewster. 1971. Lenin and Philosophy, and Other Essays. London (7 Carlisle St., W.1): NLB.

Anderson, Benedict. 1991. Imagined Communities: Reflections on the Origin and Spread of Nationalism - Revised Edition. London: Verso.

Barry, Andrew. 2001. Political Machines: Governing a Technological Society. London: Continuum.

Barthes, Roland. 1957. Mythologies. Paris.

Bourdieu, Pierre. 1979. Outline of a Theory of Practice. Cambridge University Press. 1984. Distinction: A Social Critique of the Judgement of Taste. London: Routledge \& Kegan Paul.

Bowman, P. 2016. 'The Intimate Schoolmaster and the Ignorant Sifu: Poststructuralism, Bruce Lee, and the Ignorance of Everyday Radical Pedagogy'. Philosophy and Rhetoric 49 (4): 549-70. doi:10.5325/philrhet.49.4.0549. 
Bowman, Paul. 2007. Post-Marxism Versus Cultural Studies: Theory, Politics and Intervention. Edinburgh University Press.

2008. Deconstructing Popular Culture. Palgrave Macmillan.

2010. Theorizing Bruce Lee: Film-Fantasy-Fighting-Philosophy. Rodopi.

2013a. Reading Rey Chow: Visuality, Postcoloniality, Ethnicity, Sexuality. Peter

Lang Publishing Incorporated.

2013b. Beyond Bruce Lee: Chasing the Dragon through Film, Philosophy, and Popular Culture. Columbia University Press.

2016. 'Making Martial Arts History Matter'. The International Journal of the History of Sport 33 (9): 915-33. doi:10.1080/09523367.2016.1212842.

2017. 'That Spectacular Supplement'. In Gesture and Film: Signalling New Critical

Perspectives. London: Routledge. Accessed June 7.

https://www.routledge.com/Gesture-and-Film-Signalling-New-Critical-

Perspectives/Chare-Watkins/p/book/9781138900196.

Brown, Bill. 1997. 'Global Bodies/Postnationalities: Charles Johnson's Consumer Culture'.

Representations, no. No. 58, Spring: 24-48.

Butler, Judith. 1990. Gender Trouble: Feminism and the Subversion of Identity. New York; London: Routledge.

Chow, Rey. 2012. Entanglements, or: Transmedial Thinking About Capture. A John Hope

Franklin Center Book. Durham and London: Duke University Press.

De Man, Paul. 1986. The Resistance to Theory. Theory and History of Literature ; v. 33. Minneapolis: University of Minnesota Press.

Derrida, Jacques. 1994. Specters of Marx : the state of the debt, the work of mourning, and the New international. New York; London: Routledge.

Derrida, Jacques, and Elisabeth Weber. 1995. Points - : interviews, 1974-1994. Stanford, Calif.: Stanford University Press.

Foucault, Michel. 1970. The Order of Things: An Archaeology of the Human Sciences. London: Tavistock Publications.

Frank, Adam. 2006. Taijiquan and the Search for the Little Old Chinese Man: Understanding Identity Through Martial Arts. Palgrave Macmillan.

Judkins, Benjamin N., and Jon Nielson. 2015. The Creation of Wing Chun: A Social History of the Southern Chinese Martial Arts. SUNY Press.

Laclau, Ernesto, and Chantal Mouffe. 1985. Hegemony and Socialist Strategy: Towards a Radical Democratic Politics. London: Verso.

Morris, Meaghan. 1990. 'Banality in Cultural Studies'. Discourse: Journal for Theoretical Studies in Media and Culture 10 (2).

Phillips, Scott Park. 2016. Possible Origins: A Cultural History of Chinese Martial Arts, Theater and Religion. 1 edition. Angry Baby Books.

Sacks, Sheldon. 1978. On Metaphor. Chicago: University of Chicago Press. http://www.press.uchicago.edu/ucp/books/book/distributed/O/bo3634790.html.

Sieler, Roman. 2015. Lethal Spots, Vital Secrets: Medicine and Martial Arts in South India. Oxford, New York: Oxford University Press.

Silverman, Kaja. 1983. The Subject of Semiotics. Oxford: Oxford University Press.

Singleton, Mark. 2010. Yoga Body: The Origins of Modern Posture Practice. Oxford University Press.

Spatz, Benjamin. 2015. What A Body Can Do: Technique As Knowledge, Practice As Research. London and New York: Routledge. 
Spivak, Gayatri Chakravorty. 1990. The Post-Colonial Critic: Interviews, Strategies,

Dialogues. New York; London: Routledge.

Wacquant, Löic. 2004. Body and Soul: Notebooks of an Apprentice Boxer. Oxford; New York: Oxford University Press.

Wacquant, Loïc. 2009. 'The Body, the Ghetto and the Penal State'. Qualitative Sociology, no. 32: 101-29. doi:10.1007/s11133-008-9112-2.

2013. 'Habitus as Topic and Tool: Reflections on Becoming a Prizefighter'. In Fighting Scholars: Habitus and Ethnographies of Martial Arts and Combat Sports, edited by Raúl Sánchez García and Dale C. Spencer, 19-32. London, New York, and Delhi: Anthem Press.

Wile, Douglas. 1999. T'ai-Chi's Ancestors: The Making of an Internal Martial Art. Sweet Ch'i Press.

Young, Robert J. C. 1992. 'The Idea of a Chrestomathic University'. In Logomachia: The Conflict of the Faculties, edited by Richard Rand. Lincoln and London: University of Nebraska Press.

\section{Notes}

\footnotetext{
${ }^{1}$ In the influential essay, 'Banality in Cultural Studies', Meaghan Morris argues that 'anecdotes for [her] are not expressions of personal experience, but allegorical expositions of a model of the way the world can be said to be working. So anecdotes need not be true stories, but they must be functional in a given exchange' (Morris 1990).

2 We could easily psychoanalyse this, of course. It all sounds very Oedipal. But we could also 'sociologize' it too: the supposed lack of comprehension of 'intellectual work' by working class subjects is a very Bourdieuian way to illustrate 'habitus' - as in 'how can you say you are "at work" when you are in your dressing gown reading a book?'
}

3 The Althusserian theory of 'interpellation' of course very strongly and directly involves a body that is 'turned' by being addressed by another embodiment of power (such as a police officer). But the type of cultural theory I was immersed in at this stage was much more interested in the power effects within a world conceived as a world of power relations than in the bodily effects in a world conceived of as a world of bodies.

${ }^{4}$ Practitioners and aficionados of Chinese 'internal' martial arts may disagree, and retort that in many respects the 'guts' are indeed literally the key area to discuss, as deep in the guts is where we find the dantian (dantien, or tantien).

\footnotetext{
${ }^{5}$ When I was growing up, the older generation bewailed our inability to populate blank maps of the world with country and city names. But the British Empire was no more. Former educational imperatives were now redundant. So we weren't forced to learn them.
}

${ }^{6}$ For more on the relationships between martial arts and exorcism, see Scott Park Phillips' recent fascinating study, Possible Origins: A Cultural History of Chinese Martial Arts, Theater and Religion (Phillips 2016). 